\title{
11
}

\section{Method validation in forensics and the archaeological sciences}

\author{
Vojtech Hlinka, Iman Muharam and Vanessa K. lentile \\ DNA Analysis, Forensic and Scientific Services, Queensland Health \\ 39 Kessels Rd \\ Coopers Plains \\ QLD 4108 Australia \\ Email: vojtech_hlinka@health.qld.gov.au
}

\begin{abstract}
With the development and application of scientific methods in both archaeology and forensics, it is important to test or validate these methods to ensure they can withstand rigorous scrutiny from scientific and other communities and perform as expected. Approaches to method validation within archaeological and forensic science are discussed in this paper, with a focus on outlining current forensic validation procedures. An example of how a validation process has been applied in assessing technology for quantifying human DNA from forensic samples is provided. We propose that guidelines for method validation in archaeological science could be based on those currently utilised in forensics.
\end{abstract}

\section{KEYWORDS}

validation, scientific methods, archaeology, forensics, PCR, DNA

\section{INTRODUCTION}

An increasing number of archaeological and forensic laboratories are becoming service providers for public and private institutions. With this role comes the responsibility to provide accurate scientific data using an accepted methodology that has been scrutinised and reviewed effectively through a rigorous validation procedure. This procedure is of particular importance if results are to be compared with those obtained elsewhere, for example from another laboratory, or if the results are to be included in an official report such as a contracted report from an archaeological laboratory or a statement for a court of law as is often the case in forensics. Validation ensures that results have been obtained using a proven method that is suitable for answering a specific scientific question.

\section{WHAT IS VALIDATION?}

Validation is a process by which a method is primarily assessed for:

- its adequacy to suit its intended purpose (NATA 2004);

- its reliability (SWGDAM 2004);

- whether it has suitable operational conditions for obtaining results (SWGDAM 2004); and

- its limitations (SWGDAM 2004). 
Validation is useful for achieving a number of desired outcomes. It minimises re-invention of methods in different laboratories. Methods that have been validated are more readily accepted, more easily standardised, and can be compared internationally between different laboratories. Validation also helps to identify potential limitations specific to a method or laboratory.

Many laboratories follow validation processes in order to meet specific quality standards (either informal or set at the national or international level). A validated scientific protocol will have an associated report detailing the validation process for the specific protocol that can be reviewed by external quality assessors. Because of their role in the criminal justice system, and specifically in the identification of people through analysis of DNA material, forensic laboratories in Australia are required to meet guidelines (based on the international ISO 17025 standard) set by the National Association of Testing Authorities (NATA). They must meet all quality standards that are listed in the guidelines. Non-compliance with the NATA guidelines may result in loss of accreditation and also risks loss of credibility of the laboratory with peers. Although forensic science is related to archaeological science in certain aspects such as the identification of human remains based on analysed DNA, not all archaeological laboratories operate under a set of national or international guidelines. Such guidelines may be beneficial to some archaeological science disciplines, through demonstration of standards in a universal and clearly understood manner.

Validation should be distinguished from other method-assessment processes such as verification or evaluation. Verification is the process by which collaborating lines of evidence are collected in order to determine if a method is working as expected within a specific laboratory's own conditions (operators, equipment, environment) (adapted from Hedges 2003:667). During verification, results from a few samples are compared with results obtained from other evidence. In the forensic field, this evidence is usually validation data, typically in the form of publications or reports that detail the performance characteristics of the standard method. The outcomes of the verification process are closely linked to the quality and reliability of the validation process. However, validation is a more intensive and rigorous process than verification.

Evaluation is a process by which the suitability of a method is assessed. Typically, results from a number of methods are compared to determine which is more suitable for an intended task. However, the detailed criteria encountered in a validation are not a prerequisite in this process and are only recommended for application to the method selected at the end of an evaluation.

The focus of this article is the use of the validation process as distinct from the verification and evaluation processes with which archaeological scientists may be more familiar. Validation ensures a rigorous and high standard of maintenance during any form of scientific analysis by guaranteeing that samples will be used economically and maintaining sample integrity and continuity. Integrity maintenance has two aspects: the first is avoiding contamination or deleterious handling or processing that could damage, make void or devalue evidence; the second is the avoidance of unnecessary destruction or reduction of the sample size. Both archaeological and casework forensic samples are finite and it may be necessary to use samples for other lines of evidence or for reworking, such as independent evaluation of the evidence.

For casework samples in the field of forensic science, scientific evidence needs to be admissible in court. The expert witness or reporting officer may be questioned about any obtained results and therefore must be able to convince the court of the applicability of the chosen scientific method and significance of the results in context. It is not unusual for an expert witness to be challenged on specific scientific protocols that were used by the testing laboratory, in order to scrutinise the chosen protocols and unveil any breakdowns in quality. An example of a challenge to an established forensic protocol occurred recently over the applicability of low copy number (LCN) analysis methods for the Omagh bombing case in the United Kingdom (The Crown Prosecution Service Press Release 14 January 2008). The presiding judge expressed concerns because, although the testing laboratory had internally validated and published scientific papers on the technique, there was an alleged lack of external validation by the wider scientific community. As a result, the use of LCN analysis was suspended in the UK for a short period and a full review of forensic cases involving LCN technology was ordered. 
Forensic anthropological investigation methods have also been scrutinised by courts in the past (Ubelaker 2008). For example, in the trial of The Prosecutor of the Tribunal against Radislav Krstic (Case No. IT-98-33), the validity of methods used to estimate the age at death of human remains from the Balkans was questioned because the methods were based on American standards. Because these standards were developed on the basis of a reference population dataset not necessarily representative of the Balkans skeletal population, it was argued that the methods had not been validated appropriately for the case in question (Ubelaker 2008).

\section{FORENSIC AND ARCHAEOLOGICAL SCIENCE IN AUSTRALIA}

In Australian forensic science, NATA set validation and verification guidelines and specify the minimum acceptable standards for a laboratory. DNA Analysis, Forensic and Scientific Services in Queensland Health is accredited under NATA based on ISO/IEC 17025 standards, while Quality and Management is certified ISO9001. NATA (2004) recommended components of a chemical validation include determining selectivity, linearity, sensitivity, accuracy [trueness and precision (repeatability and reproducibility)], limit of detection, limit of quantitation, range, ruggedness, and measurement uncertainty (see Table 1). Method validation is required for laboratory accreditation by ISO/IEC 17025.

Table 1. NATA (2004) recommended components of a chemical validation

\begin{tabular}{|c|c|}
\hline Component & Description \\
\hline Linearity & $\begin{array}{l}\text { Linearity or the linear response range is the range of values between which } \\
\text { the method produces a linear calibration line. Linearity can only be applied to } \\
\text { methods where a linear relationship can be established. For non-linear systems, } \\
\text { relationships can also be established in equation form and expressed as a } \\
\text { range (see range). Linearity is determined by graphing results from the replicate } \\
\text { analysis of a reference material of known composition to produce a linear } \\
\text { equation } y=m x+c \text {. In this equation } m \text { is the slope and } c \text { the } y \text {-intercept, } x \text { is the } \\
\text { value on the } x \text {-axis or the independent variable, and } y \text { is the value obtained from } \\
\text { the instrument. }\end{array}$ \\
\hline Sensitivity & $\begin{array}{l}\text { Sensitivity is a measure of the response of measurements to only slight changes } \\
\text { in the sample being tested. For linear systems, sensitivity is the slope }(m) \text { of } \\
\text { the linearity graph }(y=m x+c) \text {. A mean slope with a high positive }(\text { e.g. }>1) \text { or low } \\
\text { negative linear value }(\text { e.g. }<-1) \text { indicates that on average the method is highly } \\
\text { sensitive. }\end{array}$ \\
\hline Accuracy-Trueness & $\begin{array}{l}\text { Accuracy-trueness is a measure of how near a result is to the accepted or } \\
\text { 'true' value for the method being assessed. Accuracy-trueness is measured } \\
\text { by determining the bias or systemic error. Trueness is determined by replicate } \\
\text { analysis of a reference material of known composition. It is calculated as a } \\
\text { fraction or percentage of the measured result to the accepted or 'true' value and } \\
\text { can be assessed with a t-test. }\end{array}$ \\
\hline $\begin{array}{l}\text { Accuracy-Precision- } \\
\text { Repeatability }\end{array}$ & $\begin{array}{l}\text { Precision is the closeness of agreement between independent replicate test } \\
\text { results. Repeatability is a measure of the maximum acceptable difference } \\
\text { between two test results obtained at the same time by the same analyst under } \\
\text { identical conditions on the same material. Normally, repeatability is calculated at } \\
\text { the } 95 \% \text { confidence level (and two correctly obtained results will not differ from } \\
\text { one another by more than the repeatability value in more than } 1 \text { in } 20 \text { cases). }\end{array}$ \\
\hline $\begin{array}{l}\text { Accuracy-Precision- } \\
\text { Reproducibility }\end{array}$ & $\begin{array}{l}\text { Reproducibility is a measure of the maximum acceptable difference between } \\
\text { two test results obtained on the same material by different analysts at different } \\
\text { times. This value of reproducibility is the one generally used to estimate the limits } \\
\text { of uncertainty of a result. Inter-laboratory reproducibility is most conveniently } \\
\text { determined in collaborative trials. }\end{array}$ \\
\hline Selectivity & $\begin{array}{l}\text { Selectivity is a measure of accuracy in the presence of interference. It is tested } \\
\text { by comparing results for samples containing impurities with results for samples } \\
\text { without impurities. Single point tests are acceptable but various points with } \\
\text { varying amounts of inhibitor will add more data about the interference of different } \\
\text { amounts of a substance. }\end{array}$ \\
\hline
\end{tabular}




\begin{tabular}{|l|l|}
\hline Limit of detection & $\begin{array}{l}\text { The lower limit of detection is the lowest value for a sample that can be reliably } \\
\text { distinguished from zero, but not necessarily quantified, by the test method. It } \\
\text { is the lowest value that is greater than the uncertainty associated with it and } \\
\text { therefore is an indication of the value at which detection becomes problematic. }\end{array}$ \\
\hline Limit of quantitation & $\begin{array}{l}\text { The limit of reporting or quantitation is the lowest value that can be determined } \\
\text { with acceptable repeatability and accuracy by the test method. Depending on the } \\
\text { level of certainty required (e.g. whether or not the analysis is for legal purposes) } \\
\text { this is usually taken as three times or ten times (for greater certainty) the limit of } \\
\text { detection. }\end{array}$ \\
\hline Range & $\begin{array}{l}\text { The working range is defined as the minimum to maximum acceptable working } \\
\text { values. The minimum acceptable working value beyond any reasonable doubt is } \\
\text { the limit of quantitation. The maximum acceptable working value is the maximum } \\
\text { value that can be determined with acceptable repeatability and accuracy by the } \\
\text { test method. }\end{array}$ \\
\hline Ruggedness & $\begin{array}{l}\text { Ruggedness is a measure of how robust a method is, and therefore an } \\
\text { assessment of how changes in the normal course of performing a method can } \\
\text { affect the results. Ruggedness is tested by measuring the effects of one variable } \\
\text { at a time or a combination of variables identified as the most likely to affect } \\
\text { results. Testing is performed with controls. }\end{array}$ \\
\hline $\begin{array}{l}\text { Measurement uncertainty is a measure of the range of values that can reasonably } \\
\text { be attributed to the specific quantity being measured. It takes into account all } \\
\text { the recognised effects on a result such as overall long-term precision, bias and } \\
\text { calibration effects and uncertainties, and other effects. Measurement uncertainty } \\
\text { is usually expressed as a standard deviation or confidence interval. }\end{array}$ \\
\hline uncertainty
\end{tabular}

In addition to the basic NATA validation guidelines for accreditation in forensics, DNA Analysis, Forensic and Scientific Services in Queensland occasionally utilises Scientific Working Group on DNA Analysis Methods (SWGDAM) guidelines (SWGDAM 2004). Internal Standard Operating Procedures (SOPs) within Queensland Health ensure that validation guidelines are followed to acceptable standards. The SOPs are used and maintained internally through an intranet Quality Information System.

An example of an internal validation undertaken at DNA Analysis, Forensic and Scientific Services, Queensland Health was that of the Quantifiler Human DNA Quantitation Kit (Applied Biosystems 2003). Run on the ABI Prism 7000 SDS instrument from Applied Biosystems, it forms a real-time quantitative PCR system with in-built inhibition detection. The method determines the human DNA concentration of an extracted DNA sample and the approximate level of PCR inhibitors present. Thus, an estimate for the approximate sample volume for the amplification of DNA via PCR can be calculated from the resulting concentration. The same reaction also determines whether a sample needs further purification prior to amplification. Although the method was validated in the United States to SWGDAM guidelines (see Applied Biosystems 2003), an in-house validation at Queensland Health with external collaboration was necessary to comply with NATA guidelines.

We assessed the accuracy of the Quantifiler system in DNAAnalysis, Forensic and Scientific Services as a component of the validation process. In assessing the long-term accuracy of the system in-house it was found that specific lots of the DNA standard on average displayed a twofold bias in concentration values. Originally the average bias was corrected for and eventually, the Quantifiler standards were replaced with other standards certified at known concentrations by another manufacturer. This change resulted in a lower and more acceptable bias. Controls for the acceptance and rejection of Quantifiler runs as well as for monitoring changes in them were introduced. The lesson learnt from this process was that although a method may pass an original validation, monitoring systems in the form of suitable quality controls must be in place to demonstrate that a method continues to work acceptably over time and that conditions encountered during the original validation have not changed.

Forensic scientists occasionally misinterpret validation guidelines, leading to some incorrect views about how validations should be performed (Butler 2006). One common misinterpretation of the SWGDAM guidelines for conducting an internal validation is the belief that it is necessary 
to have 50 samples per experiment or 50 samples of the same type per experiment (Butler 2006:4). The 50 samples recommended in the guidelines actually refer to the minimum total sample size for an entire internal validation (Butler 2006:4). In summary, the sample size has to be large enough to produce statistically valid results with methods such as the Student's t-test for assessing accuracy (Butler 2006). Butler (2006) considers between five and ten samples to be sufficient for a validation experiment in forensics.

A potential difference in method validation between forensic and archaeological sciences is that in forensic science NATA guidelines state that a standard method needs to be validated by collaborative studies before its use can be verified in a laboratory. Such a method is more likely to be deemed valid in a court of law. In archaeological science, either validation or verification processes may be applied.

Archaeological method verification is used to provide evidence of whether a method is performing satisfactorily within a laboratory when compared with its published performance characteristics or a similar standard method. It is generally considered suitable when its performance exceeds or equals that of a published method. A method is therefore deemed valid if it produces the desired results and has been checked or verified internally against external published standards.

Radiocarbon dating is one example where researchers have paid significant attention to ensuring the method produces valid results in terms of accuracy. It is also an example of a scientific method that was applied to archaeological samples before a validation of the accuracy of the method was obtained. Libby first described the radiocarbon method for dating organic material in 1949 (Libby 1955). Because questions arose over the accuracy of the method (Libby 1963), Libby then tested the method against well-dated materials to validate its accuracy. Assumptions in the original method such as the constant concentration of radiocarbon in the atmosphere were subsequently shown to be incorrect, with readings from dendrochronologicallydated bristlecone pines being younger before about 1200 BC (Fagan 1991:123). It took several decades of cooperation between different laboratories to produce validated methods for obtaining reproducible calibrated radiocarbon dates (Fagan 1991:123-124). Verification of the radiocarbon method in different laboratories identified localised problems with radiocarbon dates such as the marine, estuarine and freshwater reservoir effects (e.g. Fischer and Heinemeier 2003; Ulm 2006). Over a few decades of validation and verification processes, it was demonstrated that the radiocarbon method was suitable for its intended purpose when the appropriate calibrations can be performed.

For DNA projects in the Archaeological Sciences Laboratories (ASL) at the University of Queensland in the years between 1995 to 2005, the validity of a method was commonly determined through trials on modern reference samples (e.g. control samples) and comparison of results with those from a published or accepted method. The method had to be tested on the same samples or at least samples of the same type. If successful, the test was then applied to mock archaeological samples or limited archaeological samples (e.g. unprovenanced samples). If this was successful, then the final stage involved application of the method with an aim of answering a question of archaeological significance. Successful results from subsequent independent use of the methods by researchers and students, usually in-house, meant the methods went through an archaeological 'verification' process.

An example of a method that went through this verification process was a silica and chaotropic-based DNA extraction method. This method was developed by Boom et al. (1990) and tested in other laboratories (Höss and Pääbo 1993). In the ASL, it was subsequently tested and optimised by several researchers on modern samples before being applied to archaeological samples (e.g. Hlinka 2003; Matheson 2001). A major component of testing in the ASL was comparison of results using this particular method with results obtained from other methods running comparable sample controls. Slightly modified versions of the method continue to be used by other laboratories and have been verified as suitable for archaeological samples such as bones and teeth (Rohland and Hofreiter 2007a, 2007b). However, a validation of the method 
performed to set criteria such as those outlined in Table 1, combined with a comparison of different methods validated by the same criteria, would be a more efficient system. In this way some of the comparisons made using finite archaeological samples as well as repetition of work in method testing by different researchers could have been minimised.

As a further control, Dr Tom Loy pioneered a Laboratory Information Management System called MARS (Multirelational Archaeological Research Sciences database) at the University of Queensland. MARS contained a list of standard reference methods used routinely by DNA researchers in the ASL and tracked day-to-day laboratory work. Methods deemed suitable for use through the verification process, such as the silica and chaotropic-based DNA extraction method, were listed in the database and considered validated. Methods were further verified with continued successful use by other researchers and students, both internally and externally.

In Australian archaeology, current guidelines for laboratories not bound by biohazard, quarantine, internal or other quality control regulations still include moral and ethical standards and codes such as the Code of Ethics of the Australian Archaeological Association (AAA). The AAA Code of Ethics states that methods in archaeological science used to investigate archaeological sites and materials should be utilised in ways that "conserve the archaeological and cultural heritage values of the sites and materials" (AAA 2008). The Code also advises that "... members will advocate the conservation, curation and preservation of archaeological sites, assemblages, collections and archival records" (AAA 2008). By extension, the AAA Code of Ethics therefore encourages archaeologists to utilise methods that have minimal impact on the integrity of archaeological evidence and methods where continuance of archaeological evidence can be maintained. Similarly, while research guidelines such as the Joint NHMRC/AVCC Statement and Guidelines on Research Practice (NHMRC and AVCC 1997) and the Australian Code for the Responsible Conduct of Research (NHMRC 2006) do not contain any specific validation guidelines, they do discuss peer review mechanisms that are directly applicable to determining if a method is valid.

\section{RECOMMENDATIONS}

The degree to which a method should be validated in archaeology or forensics is a balance of costs, risks and technical possibilities and depends on the status of the method and the needs and requirements relating to its application (Butler 2006). Often a method will appear complex because it can comprise several sub-methods, and it may be necessary then to validate the individual sub-methods as well as the whole system. A new in-house method will require rigorous validation whereas minor modifications to a validated in-house method may only require a few checks before implementation. The basic rule is that every method evaluated as suitable for use first requires validation, then verification.

We propose that guidelines for method validation in some fields within archaeological science could be based on those currently utilised in forensic science (e.g. NATA 2004; SWGDAM 2004), although these are intended primarily for chemical methods. Current archaeological practice for evaluating scientific methods for their suitability could be enhanced by the use of standardised criteria or parameters that can be compared intra- and inter-laboratory. Where applicable, the use of the NATA criteria would ensure a minimum standard and provide scope for more rigorous comparisons and evaluations. In addition, the publication of more rigorous methods testing in archaeological science would help in assessing the suitability of specific methods.

The forensic validation criteria presented here are skewed towards quantifiable analytical methods such as DNA research. However, archaeological excavation or processing methods could also be validated with these criteria by analysing quantifiable characteristics such as the number and types of artefacts recovered from mock and archaeological sites. The criteria would need to be adapted in cases such as the validation of reconstruction methods (e.g. pottery, bone and site reconstructions). 
In addition to the validation criteria, we also recommend the creation of a database of standardised methods that have been validated externally and that are recommended for in-house validation and verification to avoid 're-inventing the wheel'.

\section{CONCLUSION}

Validation is a necessary process in both forensics and archaeological science. Adoption of the forensic validation model presented here could provide a framework for application in many areas of archaeological science. The validation process ensures that methods are standardised and comparable and hence more readily acceptable internationally.

\section{ACKNOWLEDGEMENTS}

We would like to dedicate this article to the memory of Dr. Tom Loy. We thank the members of the Archaeological Sciences Laboratories, the School of Social Science and the Institute for Molecular Bioscience at the University of Queensland, and the members of Forensic and Scientific Services, Queensland Health.

\section{REFERENCES}

AAA (Australian Archaeological Association) 2008.

www.australianarchaeologicalassociation.com.au/ethics.htm Accessed $29^{\text {th }}$ May, 2008.

Applied Biosystems 2003. Quantifiler ${ }^{\mathrm{TM}}$ Kits Quantifiler ${ }^{\mathrm{TM}}$ Human DNA Quantification Kit and Quantifiler ${ }^{\mathrm{TM}}$ Y Human Male DNA Quantification Kit User's Manual, pp.175.

Boom, R., Sol, C.J., Salimans, M.M., Jansen, C.L., Wertheim-van Dillen, P.M., and J. van der Noordaa 1990. Rapid and simple method for purification of nucleic acids. Journal of Clinical Microbiology 28:495-503.

Butler, J. 2006. Debunking some urban legends surrounding validation within the forensic DNA community. Profiles in DNA September 2006:3-6.

Fagan, B.M. 1991. In The Beginning: An introduction to archaeology. $7^{\text {th }}$ edition. New York: Harper Collins Publishers.

Fischer, A. and Heinemeier, J. 2003. Freshwater reservoir effect in 14C dates of food residue on pottery. Radiocarbon 45(3):449-466.

Hedges, R. 2003. Puzzling out the past. Nature 422:667.

Hlinka, V. 2003. Genetic Speciation Of Archaeological Fish Bones. Unpublished PhD thesis. School of Social Science, University of Queensland.

Höss, M. and Pääbo 1989. DNA extraction from Pleistocene bones by a silica-based purification method. Nucleic Acids Research 21:3913-3914.

Libby, W.F. 1955. Radiocarbon Dating. Chicago: University of Chicago Press.

Libby, W.F. 1963. The accuracy of radiocarbon dates. Antiquity 37:213-219.

Matheson, C. 2001. Genetic Analysis Of Human Population Groups And Subgroups From Samples Of Degraded DNA. Unpublished PhD thesis. Department of Biochemistry, University of Queensland. 
NATA (National Association of Testing Authorities) 2004. Guidelines for the Validation and Verification of Chemical Test Methods. Technical Note 17.

NHMRC and AVCC 1997. Joint NHMRC/AVCC Statement and Guidelines on Research Practice. www.nhmrc.gov.au/funding/policy/researchprac.htm Accessed 31 January, 2007.

NHMRC 2006. Australian Code for the Responsible Conduct of Research www.nhmrc.gov.au/ funding/policy/code.htm. Accessed 31 January, 2007.

Rohland, N. and Hofreiter, M. 2007a. Ancient DNA extraction from bones and teeth. Nature Protocols 2(7): 1756-1762.

Rohland, N. and Hofreiter, M. 2007b. Comparison and optimization of ancient DNA extraction. BioTechniques 42(3):343-352.

SWGDAM 2004. Scientific Working Group on DNA Analysis Methods (SWGDAM) 2004 Revised Validation Guidelines Forensic Science Communications 6(3):1-6.

The Crown Prosecution Service (UK) 2008. Press Release 14 January 2008: "Review of the use of Low Copy Number DNA analysis in current cases". www.cps.gov.uk/news/ pressreleases/101_08.html. Accessed 10 July 2008.

Ubelaker, D.H. 2008. Issues in the global applications of methodology in forensic anthropology. Journal of Forensic Sciences 53(3): 606-607.

Ulm, S. 2006. Marine and estuarine reservoir effects in central Queensland: determination of $\Delta \mathrm{R}$ values. In Coastal Themes: An Archaeology of the Southern Curtis Coast, Queensland. Terra Australis 24: 47-64. 